\title{
Preliminary paleomagnetic study of Cretaceous dykes in SE-Tibet
}

\author{
B Antolín ${ }^{1 *}$, E Appel $^{1}$, I Dunkl ${ }^{2}$, L Ding ${ }^{3}$, C Montomoli ${ }^{4}$ El Bay ${ }^{1}$ R and R Gloaguen ${ }^{5}$ \\ 1 Institutf. Geowissenschaften, Sigwartstrasse 10. D-72076 Tübingen, GERMANY \\ 2 University of Göttingen, Goldschmidtstrasse 3, D-37077 Göttingen, GERMANY \\ 3 Institute of Tibetan Plateau Research, Chinese Academy of Sciences, Shuangqing Rd. 18, Beijing 100085, CHINA \\ 4 University of Pisa, via S. Maria 53, 56126 Pisa, ITALY \\ 5 University of Freiberg, Bernhard-von-Cottastrasse 2, 09596 Freiberg, GERMANY \\ * For correspondence, email:borja.antolin@uni-tuebingen.de
}

The SE Tibetan area is a key region to better understand Tibetan Plateau formation. Lateral motion is evident by the alignment of major rivers in Southeast Asia and GPS velocities indicating motion around and away from the Eastern syntaxis. We try to find vertical axes rotations utilizing paleomagnetic studies combined with geological-petrological investigations to clarify the process of uplift of the Himalaya-Tibetan Plateau in the south eastern Tibet.

A total of 17 sites with about 10 cores per site were drilled in Lower Cretaceous diorite dykes. These dykes intruded widespread into the Triassic flysch of the Tethyan Himalaya. A total of 11 dykes were drilled in Nagarze area and 6 sites more to the east (south of Tsetang-Gyaca) (Figure 1).

Rock magnetic analysis demonstrates the presence of pyrrhotite as the principle carrier of the remanence. IRM saturates from $300 \mathrm{mT}$ to $500 \mathrm{mT}$ and thermal demagnetization of SIRM is mainly achieved around the Curie temperature of pyrrhotite $\left(325^{\circ} \mathrm{C}\right)$. Most of the samples show also a decay of the SIRM around $580^{\circ} \mathrm{C}$ indicating the additional presence of magnetite.

The values of the intensity of the natural remanent magnetization varies strongly from 0.5 to $446 \mathrm{~mA} \backslash \mathrm{m}$. In about $50 \%$ of the samples it is possible to isolate a significant pyrrhotite component, usually unblocking between $250^{\circ} \mathrm{C}$ and $350^{\circ} \mathrm{C}$. Equal area projection mostly shows a scattered distribution of the pyrrhotite components. In three sites the characteristic pyrrhotite remanence components are well grouping and in four sites a small circle distribution can be observed. We relate the origin of the pyrrhotite remanence to last metamorphic cooling in the area (K/Ar ages indicate $\sim 24 \mathrm{Ma}$ ). Sulphor for pyrrhotite formation has been likely delivered from the adjacent schists during peak metamorphism. The remanence is therefore probably secondary,

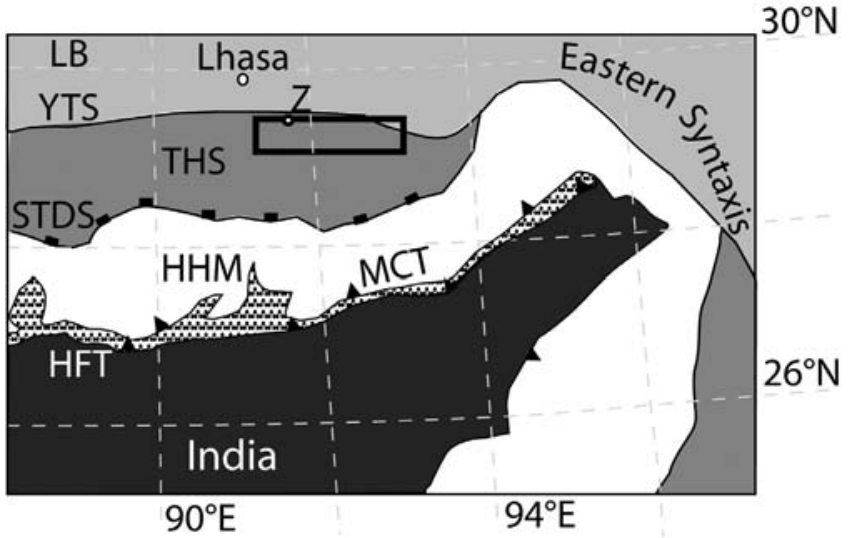

FIGURE1. Simplified geological map of the East Himalaya and SE-Tibet (modified after Yin and Harrison 2000). HFT, Himalaya Frontal Thrust; MCT, Main Central Thrust; HHM, High Himalaya Metamorphic rocks; STDS, South Tibetan Detachment System; THS, Tethyan Himalayan Sequences; YTS, Yarlung Tsangpo Suture zone; LB, Lhasa Block; Z, locality of Tsetang or Zetang. The black rectangle indicates the studied area.

either being a thermoremanence or a thermo-chemical remanence. More paleomagnetic analysis is required to elucidate vertical axes rotations in SE-Tibet.

\section{References}

Yin A and TM Harrison. 2000. Geologic evolution of the HimalayanTibetan orogen. Annual Reviews in Earth and Planetary Sciences 28: 211-280 